\title{
Precise determination of Sr/Ca by laser ablation ICP-MS compared to ICP-AES and application to multi-century temperate corals
}

\author{
Yuta Kawakubo, ${ }^{1,2}$ Yusuke Yokoyama,,${ }^{1,2,3 *}$ Atsushi Suzuki,${ }^{4}$ TaKashi OKaI, ${ }^{4}$ Chantal Alibert,${ }^{5}$ \\ LESLIE KINSLEY ${ }^{5}$ and STEPHEN EGGINS ${ }^{5}$ \\ ${ }^{1}$ Atmosphere and Ocean Research Institute, The University of Tokyo, 5-1-5 Kashiwanoha, Kashiwa, Chiba 277-8564, Japan \\ ${ }^{2}$ Department of Earth and Planetary Science, Graduate School of Science, The University of Tokyo, \\ 7-3-1 Hongo, Bunkyo-ku, Tokyo 113-0033, Japan \\ ${ }^{3}$ Institute of Biogeosciences, Japan Agency for Marine-Earth Science and Technology, \\ 2-15 Natsushima, Yokosuka, Kanagawa 237-0061, Japan \\ ${ }^{4}$ Geological Survey of Japan, National Institute of Advanced Industrial Science and Technology (AIST), \\ 1-1-1 Higashi, Tsukuba, Ibaraki 305-8567, Japan \\ ${ }^{5}$ Research School of Earth Sciences, Australian National University, Australia
}

(Received August 31, 2013; Accepted November 18, 2013)

\begin{abstract}
Coral skeletal $\mathrm{Sr} / \mathrm{Ca}$ compositions are valuable tools for the reconstruction of past tropical climate. While solutionbased ICP-AES has become the preferred method to obtain monthly-resolved $\mathrm{Sr} / \mathrm{Ca}$ records as proxy for sea-surface temperature (SST), laser ablation ICP-MS (LA-ICP-MS) allows a more rapid and still precise analysis of multiple elemental ratios at higher spatial resolution and, measurements can easily be replicated. However, the methodology still needs to be refined for long corals. It is applied here to a 435 year old Porites coral from the temperate region of southern Japan. Sr/Ca ratios measured by LA-ICP-MS and ICP-AES for three 10-15 yr periods are shown to be highly consistent. Resolution, data processing and $\mathrm{Sr} / \mathrm{Ca}$-SST calibration issues are discussed, and a replicate strategy is proposed to ensure high-precision $\mathrm{Sr} / \mathrm{Ca}$ records from multi-century corals using LA-ICP-MS.
\end{abstract}

Keywords: coral, $\mathrm{Sr} / \mathrm{Ca}$, laser ablation ICP-MS, ICP-AES

\section{INTRODUCTION}

Coral skeletal $\delta^{18} \mathrm{O}$ and $\mathrm{Sr} / \mathrm{Ca}$ compositions which reflect environmental conditions such as SST and salinity in ambient seawater at the time of calcification, are good proxies for reconstructing past tropical climates and understanding climate variability at various timescales (Felis et al., 2009; Yokoyama et al., 2011; Nurhati et al., 2011; Seki et al., 2012; DeLong et al., 2012). However, although $\delta^{18} \mathrm{O}$ in coral skeleton depends on both SST and seawater $\delta^{18} \mathrm{O}$ composition, $\mathrm{Sr} / \mathrm{Ca}$ is a proxy for SST alone (Beck et al., 1992). Recent culturing study has confirmed that coral $\mathrm{Sr} / \mathrm{Ca}$ is a reliable SST proxy due to its insensitivity to variations in skeletal growth rate (Hayashi et al., 2013). Inductively-coupled plasma atomic emission spectrometry (ICP-AES) has become the most common method for $\mathrm{Sr} / \mathrm{Ca}$ analysis (Schrag, 1999), partly because measurements can be done on splits of milled coral pow-

*Corresponding author (e-mail: yokoyama@aori.u-tokyo.ac.jp) Copyright @ 2014 by The Geochemical Society of Japan. der taken for oxygen isotope analysis. Solution-based analytical methods are, however, destructive and require a large amount of sample and complex chemical preparation prior to analysis. These techniques include thermal ionization mass spectrometry (TIMS) (Beck et al., 1992; Alibert and McCulloch, 1997) and high-resolution ICPMS (Felis et al., 2009). Coral analyses using in-situ microbeam techniques such as secondary ion mass spectrometry (SIMS) have given insights into biomineralization processes (Hart and Cohen et al., 1996; Allison and Finch, 2004). LA-ICP-MS allows a rapid measurement of multiple elemental ratios in coral skeleton at a much larger spatial scale than SIMS and is better suited to monthly-resolved reconstructions of past SST and other environmental parameters (Sinclair et al., 1998; Sinclair, 2005; Fallon et al., 1999, 2003). This technique has been previously used for a coral from the western Pacific Warm Pool (Alibert and Kinsley, 2008). Although the $\mathrm{Sr} / \mathrm{Ca}$ record was carefully replicated along multiple tracks, the small SST annual range in the equatorial region makes the application of the $\mathrm{Sr} / \mathrm{Ca}$ thermometer challenging. Temperate corals are better suited to allow the refinement of analytical protocols and assess the long- 
term accuracy of $\mathrm{Sr} / \mathrm{Ca}$ ratios for multi-century records.

We have used here the LA-ICP-MS technique to analyze a modern $435 \mathrm{yr}$ old Porites coral collected at Kikai Island (central Ryukyu Islands). The reproducibility of $\mathrm{Sr} / \mathrm{Ca}$ ratios along different transects of coral growth is investigated. We also compare $\mathrm{Sr} / \mathrm{Ca}$ ratios obtained by LA-ICP-MS with solution ICP-AES analyses for three 10-15 yr time-windows to assess the consistency and accuracy of $\mathrm{Sr} / \mathrm{Ca}$ ratios obtained by the laser ablation technique. The effect of data resolution on the Sr/Ca-SST calibration is discussed, and we show the advantage of the laser ablation technique to capture the winter signal associated with slow coral growth. This is important to understand past climate decadal variability as the Kuroshio current (Liu et al., 2005; Qiu, 2000, 2003), the Pacific Decadal Oscillation (Mantua et al., 1997) and the East Asian Winter Monsoon (EAWM) (Jhun and Lee, 2004) have an impact on regional SSTs mainly during winter time.

\section{Materials AND Methods}

A core from a massive Porites coral colony was collected in June 2009 with an hydraulic drill, in $3.5 \mathrm{~m}$ water depth, on the southeast coast of Kikai Island $\left(29^{\circ} 19^{\prime}\right.$ $\mathrm{N}, 130^{\circ} \mathrm{E}$ ). This core is $440 \mathrm{~cm}$ long and has been dated back to A.D. $1575 \pm 1 \mathrm{yr}$. This age was determined by counting annual bands in conjunction with the $\mathrm{Sr} / \mathrm{Ca}$ seasonal patterns. Annual bands are very clear both on $\mathrm{X}$ ray images (Fig. 1a) and also under ultraviolet (UV) light. They consist of a thin low-density band deposited during the winter months, as determined by LA-ICP-MS analysis, and a wider high-density band.

The three time windows (A.D. 1994-2004, 1700-1711 and 1671-1684) are selected to compare both in situ and solution ICP-AES techniques includes two period of the Little Ice Age (LIA). Sr/Ca analysis for 1671-1684 using LA-ICP-MS indicates distinctive colder temperature, which is ideal for testing the consistency between the two methods.

Coral slices $25 \mathrm{~mm}$ wide and up to $100 \mathrm{~mm}$ long were cut to fit the sample stage. Prior to analysis, all coral pieces were cleaned in high-purity water using a highenergy ultrasonic probe to remove loose particulates. The top few centimeters were also cleaned in an ultrasonic bath with $30 \%$ hydrogen peroxide $\left(\mathrm{H}_{2} \mathrm{O}_{2}\right)$ to remove remains of coral tissue. A few entire pieces were cleaned with $\mathrm{H}_{2} \mathrm{O}_{2}$ when necessary (see later section). LA-ICPMS analyses were conducted at the Research School of Earth Sciences (Australian National University) using a Varian 820-MS quadrupole ICP-MS equipped with an ArF excimer laser $(193 \mathrm{~nm})$. The methodology and strategy of analyses are similar to described in Fallon et al. (1999) and Alibert and Kinsley (2008). Ablation of the coral was

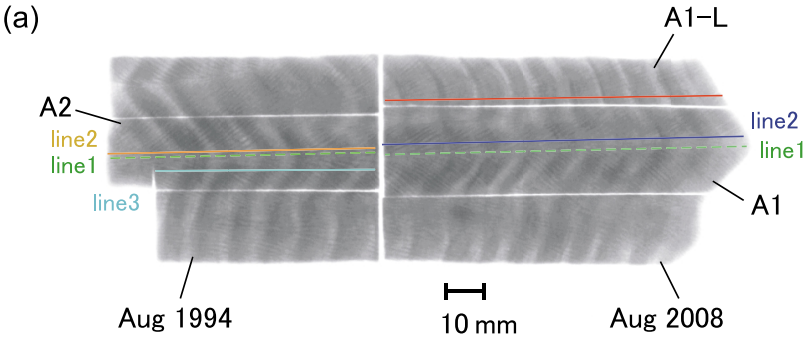

(b) Distance from top (mm)
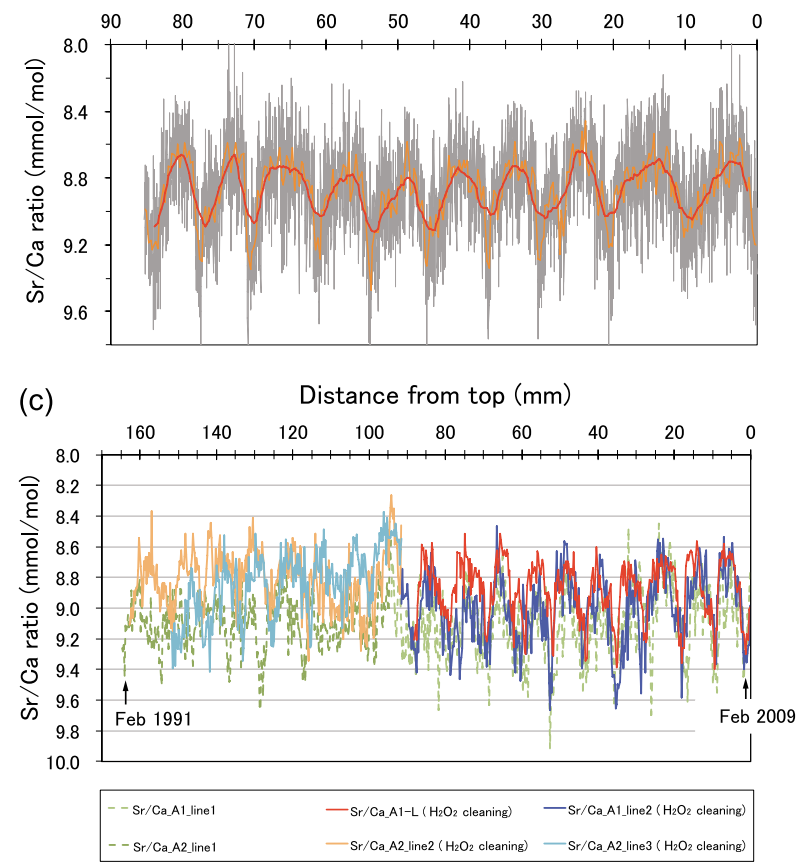

Fig. 1. (a) Positive soft X-ray photograph of a slice of the Porites coral from Kikai Island. Replicates were analyzed along different transects (lines 1 to 3 ) in pieces A1, A2 and also in piece Al-Left (Al-L). Note the regular thin low-density bands (white). (b) Sr/Ca variations versus distance showing the highresolution LA-ICP-MS data (gray line) and two smoothed curves: a simple 11-point average (orange line), and a secondstep 11 -point running average (red line). (c) LA-ICP-MS Sr/Ca variations versus distance for parallel transects. The track on A1-L was fitted to line 2 on A1, and A2 line 3 to A2 line 2, to correct for slightly different extension rates. Note anomalously high and noisy records obtained for line 1 in both pieces Al and $\mathrm{A} 2$ before treatment with $\mathrm{H}_{2} \mathrm{O}_{2}$ (green dashed line) but good reproducibility of analyses after treatment between A2 lines 2 and 3 , and between Al line 2 and the transect in piece Al-L.

done, using a $400 \times 40 \mu \mathrm{m}$ rectangular slit, at an energy density of $\sim 7 \mathrm{~J} / \mathrm{cm}^{2}$ and a pulse rate of $5 \mathrm{~Hz}$. The narrow dimension of the rectangle was scanned along the growth direction of the coral at a speed of $40 \mu \mathrm{m} / \mathrm{s}$. Measured 
isotopes included ${ }^{11} \mathrm{~B},{ }^{43} \mathrm{Ca},{ }^{25} \mathrm{Mg},{ }^{86} \mathrm{Sr},{ }^{137} \mathrm{Ba}$ and ${ }^{238} \mathrm{U}$, using a dwell time of $\sim 50$ milliseconds, with a total cycle time of $0.5 \mathrm{~s}$. Large signals for ${ }^{43} \mathrm{Ca}$ and ${ }^{86} \mathrm{Sr}$ were measured in medium attenuation mode (reduced detector sensitivity). A pressed coral powder was used as calibration standard and allowed for drift correction. This coral standard was previously analyzed by TIMS for $\mathrm{Sr} / \mathrm{Ca}$ (Alibert and Kinsley, 2008) and solution ICP-MS for other elemental ratios (Fallon et al., 1999). Reproducibility for this standard is $\pm 1.1 \%$ for $\mathrm{Sr} / \mathrm{Ca}$ (24 runs), based on the standard deviation of background and drift-corrected $\mathrm{Sr} / \mathrm{Ca}$ ratios for bracketing standards. Homogeneity of the standard pellet was verified and related uncertainties are negligible as long as a sufficient amount is analyzed (at least 2-3 mm). Repeat analyses along the same track gave a typical reproducibility in the range $0.1-0.7 \%$. Quality control was monitored by requiring a drift of less than $\sim 2 \%$ for $\mathrm{Sr} / \mathrm{Ca}$ between the bracketing standard analyses. The data-reduction program allows to remove occasional large outliers (large intensity spikes) produced by the ICPMS. The measurement of overlapping transects was further used as a quality control to maintain the accuracy of elemental ratios between consecutive coral pieces. Occasional offsets in absolute $\mathrm{Sr} / \mathrm{Ca}$ ratios were seen, which can be ascribed either to the presence of minor secondary aragonite, standard heterogeneity due to the short length analyzed, or sub-optimal coral track not sufficiently well aligned with a growth vector.

Solution based ICP-AES (IRIS Advantage, Thermo Electron) analyses were conducted on an adjacent coral slice micro-sampled continuously at a $400 \mu \mathrm{m}$ interval along the major growth axis, according to the procedure described by Gagan et al. (1998). Each sample corresponds to a volume of coral skeleton of $c a .2 \mathrm{~mm}^{3}(0.4$ $\mathrm{mm} \times 2 \mathrm{~mm} \times 2 \mathrm{~mm})$. For each sample, $100 \pm 5 \mu \mathrm{g}$ of powder was dissolved in $5 \mathrm{~mL}$ of $2 \% \mathrm{HNO}_{3}$ and analyzed using the JCp-1 coral standard (Okai et al., 2002). $\mathrm{Sr} / \mathrm{Ca}$ reproducibility of the $\mathrm{JCp}-1$ standard is $0.4 \%(2 \sigma)$.

\section{Data Processing}

Smoothing of the high-resolution $\mathrm{Sr} / \mathrm{Ca}$ data produced by LA-ICP-MS is necessary before transforming the record into a time-series. The smoothing aims at minimizing analytical noise as well as fine-scale heterogeneities of coral composition that is not dependent on temperature (e.g., Allison and Finch, 2004; Meibom et al., 2008). An additional natural smoothing of the coral record occurs by thickening of the newly-accreted skeleton over a period of a few weeks (Wall and Nehrke, 2012), which further limits the significance of very highresolution isotopic or $\mathrm{Sr} / \mathrm{Ca}$ data. This natural smoothing may explain why the $\mathrm{Sr} / \mathrm{Ca}$ signal near the top of the coral indicates colder temperatures than expected for the date

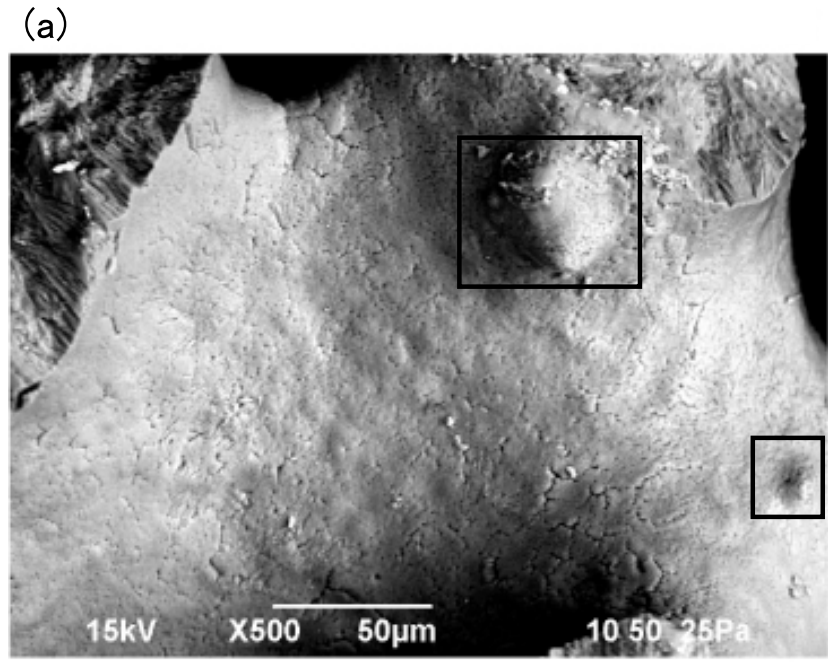

(b)

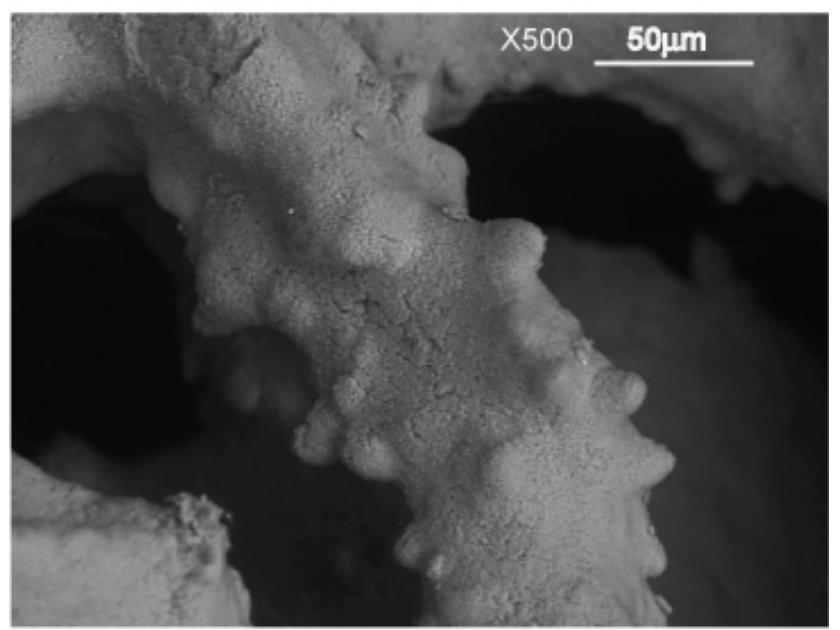

Fig. 2. Scanning electron microscope (SEM) images of the coral skeleton at the magnification X500. A small sliver of coral was broken off the edge of coral slice used for LA-ICP-MS analysis. (a) shows the small piece in A7 with clear pore surface except for a conical structure near the top and right (black windows). (b) shows secondary aragonite cones presumably deposited over fungal hyphae (LeCampion-Alsumard et al., 1995) in the piece corresponding to the early 1980s.

of collection. Data processing should therefore aim at a resolution close to bi-weekly, as done in some previous studies (Fallon et al., 1999). The annual range of SST is $7^{\circ} \mathrm{C}$ at the latitude of Kikai Island $\left(29^{\circ} \mathrm{N}\right)$. The winter minimum SST is $\sim 21^{\circ} \mathrm{C}$ that causes reduced coral growth, as shown by the narrow $\mathrm{Sr} / \mathrm{Ca}$ curve compared to instrumental SSTs (Fig. 1b). In order to capture the winter SST, 11 time-slices of data were averaged, corresponding to $250 \mu \mathrm{m}$ resolution, hence $\sim 2$-weeks of coral growth (Fig. $1 b)$. This reduces considerably the size of the data files. However, since the coral grows twice as fast in summer, 
(a)

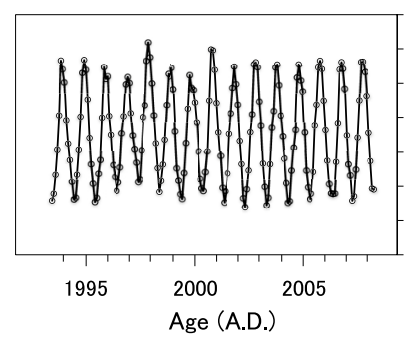

(c)

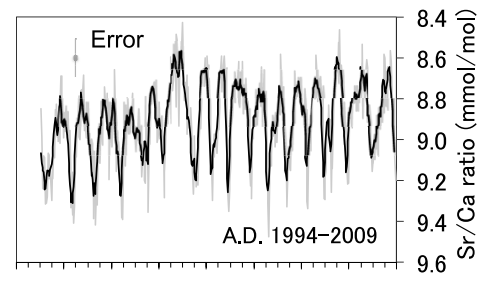

$160140120100 \quad 80 \quad 60 \quad 40 \quad 20 \quad 0$

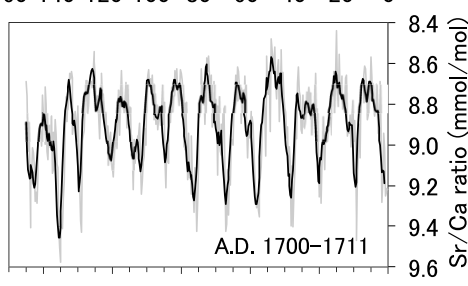

$\begin{array}{llllll}100 & 80 & 60 & 40 & 20 & 0\end{array}$

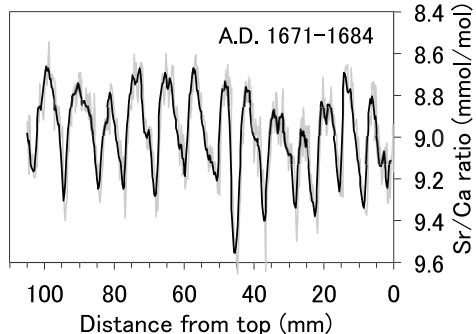

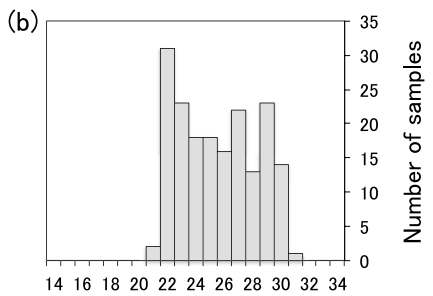

SST $\left({ }^{\circ} \mathrm{C}\right)$

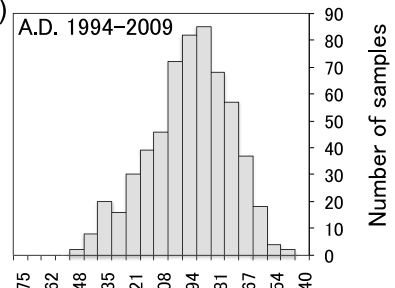

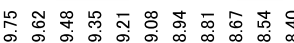

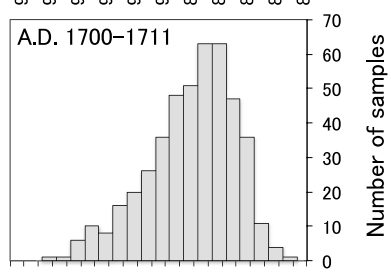

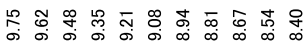

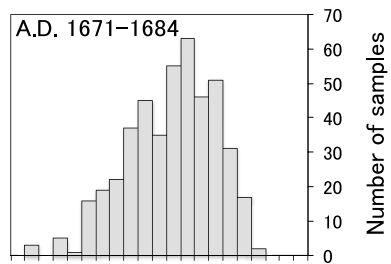

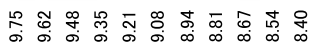

$\mathrm{Sr} / \mathrm{Ca}$ ratio $(\mathrm{mmol} / \mathrm{mol})$

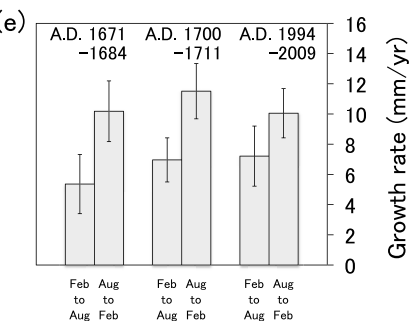

Fig. 3. (a) Monthly SSTs from the IGOSS data set (available online at: http://iridl.ldeo.columbia.edu/; Reynolds et al., 2002) at $28.5^{\circ} \mathrm{N}, 129.5^{\circ} \mathrm{E}$. The average and annual range for the 15 years between Jan-1994 and 2009 are $25^{\circ} \mathrm{C}$ and $7^{\circ} \mathrm{C}$, respectively. Dates, e.g., 1994, are given as August-1994. (b) Histogram of monthly SSTs with $1{ }^{\circ} \mathrm{C}$ bins. (c) LA-ICP-MS Sr/Ca record versus distance for 1994-2004, 1700-1711 and 1671-1684. Records are plotted as 11-point average (gray line) and a 5-point running average (black line). The $\mathrm{Sr} / \mathrm{Ca}$ error bar of $1.1 \%$ ( $1 \sigma$ standard deviation) corresponds to $\sim 1.5^{\circ} \mathrm{C}$. (d) Corresponding histograms (bin interval of $0.068 \mathrm{mmol} / \mathrm{mol}$ ) confirm the greater abundance of points in summer and mid-seasons compared to SSTs. (e) Growth rate for two 6-month periods, averaged over the three time-windows, based on matching coral Sr/Ca minimum/maximum to SST max/min values for each annual cycle. Error bar is $1 \sigma$ standard deviation of the growth rate.

$\mathrm{Sr} / \mathrm{Ca}$ data need further smoothing for the summer period to bring the resolution to bi-weekly, in a consistent way as done for winters. An 11-pt running average was chosen for this second-step smoothing, which allows to determine the $\mathrm{Sr} / \mathrm{Ca}$ minimum with greater confidence (Fig. 1b). A 5-pt running average was also used to visualize the $\mathrm{Sr} / \mathrm{Ca}$ record, but this results in an over/under smoothed $\mathrm{Sr} / \mathrm{Ca}$ record during winter/summer.

Proper comparison between LA-ICP-MS and ICP-AES data requires averaging the former to the $400 \mu \mathrm{m}$ resolu- 


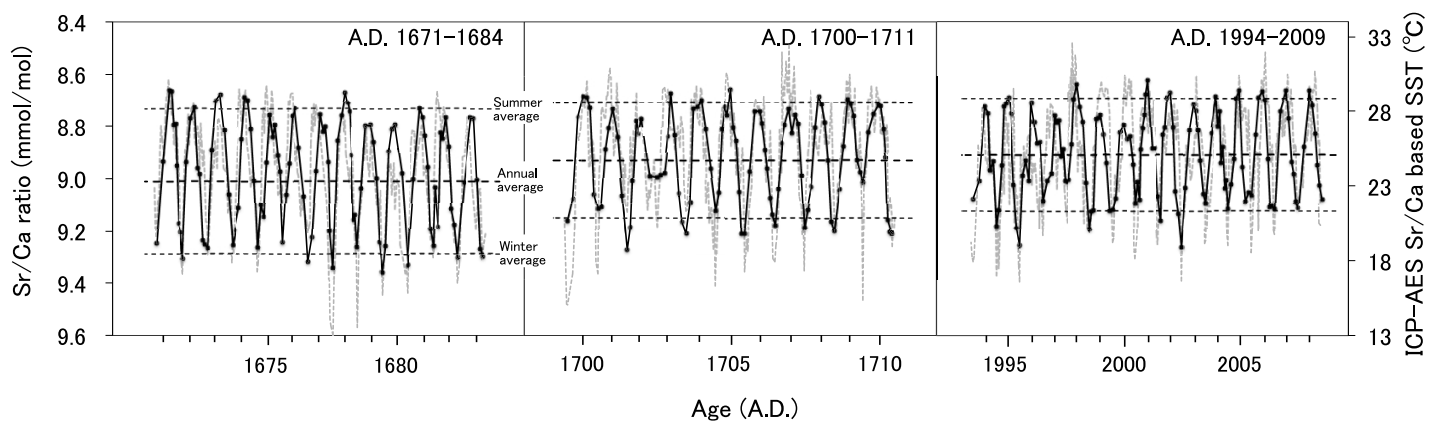

Fig. 4. Sr/Ca ratios for three time-window (1994-2004, 1700-1711 and 1671-1684) obtained by LA-ICP-MS (gray dotted line) and ICP-AES (black line, circles). We use 18-pt simple average LA-ICP-MS Sr/Ca ratio to fit to the $400 \mu \mathrm{m}$ resolution used for micro-sampling of coral powder. Summer (winter) average is the average of the minimum (maximum) ICP-AES Sr/Ca ratio in each year. Annual average is the average of the summer and winter Sr/Ca ratio. Dates, e.g., 1995, are for August-1995. Second yaxis is the ICP-AES based Sr/Ca SST using the equation given in Fig. 6.

Table 1. Average Sr/Ca ratios and amplitude of seasonal variations obtained by LA-ICP-MS and ICP-AES for three time-windows. Sr/Ca ratio obtained by LA-ICP-MS were averaged at the same 400 microns resolution used for coral milling.

\begin{tabular}{|c|c|c|c|c|c|c|}
\hline \multirow[b]{2}{*}{$\mathrm{Sr} / \mathrm{Ca}$} & \multicolumn{2}{|c|}{ A.D. $1994-2009$} & \multicolumn{2}{|c|}{ A.D. $1700-1711$} & \multicolumn{2}{|c|}{ A.D. $1671-1684$} \\
\hline & LA-ICP-MS & ICP-AES & LA-ICP-MS & ICP-AES & LA-ICP-MS & ICP-AES \\
\hline Average $(\mathrm{mmol} / \mathrm{mol})$ & 8.90 & 8.91 & 8.89 & 8.92 & 8.98 & 8.98 \\
\hline Annual variation (\%) & 10.26 & 7.15 & 11.15 & 6.87 & 10.85 & 7.75 \\
\hline
\end{tabular}

tion used for micro-sampling. Previous studies at high resolution, either using SIMS (Allison and Finch, 2004) or LA-ICP-MS (Fallon et al., 1999; Alibert and Kinsley, 2008) have highlighted that solution analysis tends to over-smooth the record due to the large volume of powder milled. As the average coral extension rate is $\sim 9 \mathrm{~mm} /$ yr, that the ICP-AES data are expected to have a resolution close to monthly.

\section{RESULTS AND DISCUSSION}

Reproducibility of Sr/Ca ratios using LA-ICP-MS

To test reproducibility, we analyzed different transects in the top two pieces of the coral core (Fig. 1a). The Sr/ $\mathrm{Ca}$ variations for A1-line 1 and A2-line 1 were initially noisy, poorly reproducible (up to $2 \%$ offset), and associated with anomalously high $\mathrm{Mg} / \mathrm{Ca}$ values. $\mathrm{A}_{2} \mathrm{O}_{2}$ cleaning procedure applied to coral pieces $\mathrm{A} 1$ and $\mathrm{A} 2$ improved the reproducibility of all elemental ratios (Fig. 1c). It is likely that some secondary aragonite is responsible for these anomalous compositions, as suggested by a patchy color of the skeleton and some less clear annual bands, as seen under UV light, between the 1970s and the top of the coral. Scattered crystals of secondary aragonite were rarely detected on scanning electron microscope (SEM) images of the coral skeleton in a thin wafer of A7 (Fig. 2a). By contrast, secondary aragonite cones deposited over fungal remains are abundant in two pieces further down corresponding to the early 1980s (Fig. 2b) and early 1960s. As the laser ablates coral skeletal surfaces, this technique is very sensitive to the presence of a small amount of secondary aragonite, compared to bulk analysis. An additional transect in the adjacent piece A1-L, produced a more reliable $\mathrm{Sr} / \mathrm{Ca}$ record with good seasonal cycle, without resorting to $\mathrm{H}_{2} \mathrm{O}_{2}$ cleaning. We then obtain good agreement between the different transects (A1$\mathrm{L}$ and $\mathrm{A} 1$-line2; A2-line2 and A2-line3), both in mean $\mathrm{Sr} /$ $\mathrm{Ca}$ and seasonal amplitude (Fig. 1c). For coral pieces showing poor $\mathrm{Sr} / \mathrm{Ca}$ reproducibility, use of $\mathrm{H}_{2} \mathrm{O}_{2}$ was proved efficient in removing the secondary aragonite.

\section{LA-ICP-MS Sr/Ca variations for three time-windows}

Monthly SST variation from A.D. 1994-2004 and Sr/ Ca variations for the periods A.D. 1994-2004, 1700-1711 and 1671-1684 are shown in Figs. 3a and c. The three periods show similar narrow winters (high $\mathrm{Sr} / \mathrm{Ca})$ and wide summer-autumn (low $\mathrm{Sr} / \mathrm{Ca}$ ), reflecting the nonuniform coral extension rate. Histograms of $\mathrm{Sr} / \mathrm{Ca}$ datapoints confirm this significant bias toward summer values when compared to monthly SSTs (Figs. $3 b$ and d). A similar "arched" $\mathrm{Sr} / \mathrm{Ca}$ annual pattern has been reported for another temperate coral from Shirigai Bay $\left(32^{\circ} \mathrm{N}\right)$ 

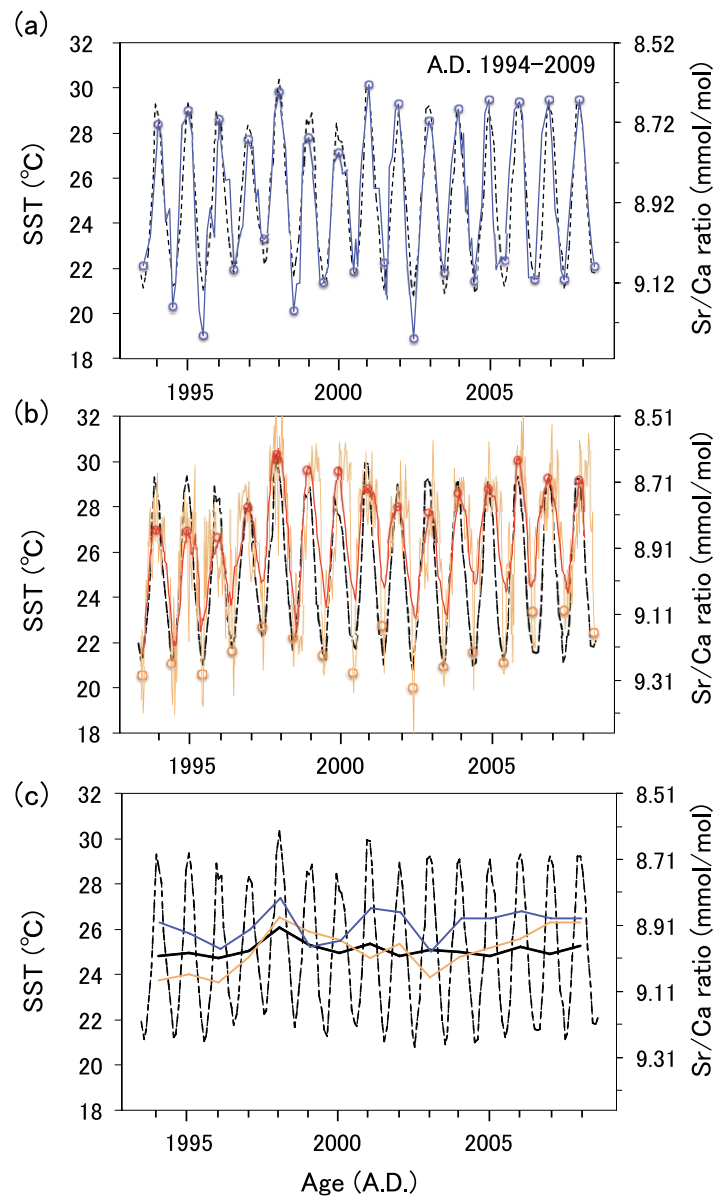

Fig. 5. (a) ICP-AES Sr/Ca record (blue line, circles) calculated as time-series by fitting 2 points per year (August and February) to monthly SSTs (black line). Second y-axis is the ICP-AES based Sr/Ca SST using the calibation equation (b) Calibration of the LA-ICP-MS Sr/Ca record to monthly SSTS (black line) using two different smoothing curves to account for the faster coral growth rate in summer relative to winter: a 11-pt average (orange profile) with a second-step 11-pt running average (red profile). As a few data-points were selected to define each min/max $\mathrm{Sr} / \mathrm{Ca}$ values, circles can be considered as best estimates for winter minimum (Jan-Feb-Mar) (orange circles) and summer maximum temperatures (Jul-Aug-Sep) (red circles). Second y-axis is the LA-ICP-MS based Sr/Ca SST using the calibration equation. (c) Annual averaged temperatures from 1994 to 2008 based on monthly SSTs (black line), ICPAES Sr/Ca record (blue line) and LA-ICP-MS Sr/Ca record (orange line). Annual average temperature is the average between maximum and minimum temperature. Second y-axis is the LAICP-MS based Sr/Ca SST using the equation presented in Fig. 6.

(Fallon et al., 1999) where winter water temperatures as low as $15^{\circ} \mathrm{C}$ suppress entirely the coral growth. Assigning the maximum $\mathrm{Sr} / \mathrm{Ca}$ to February and the minimum to August allows to calculate an average growth rate for each

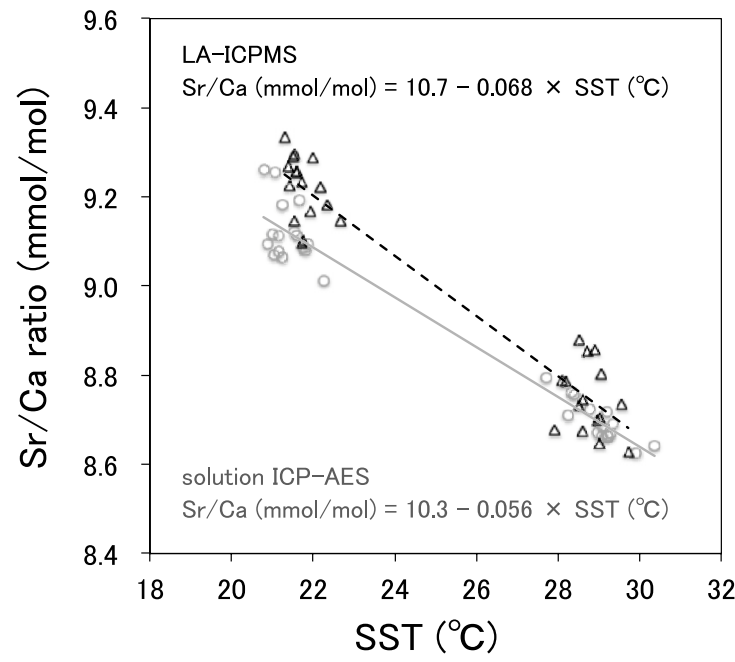

Fig. 6. Sr/Ca calibration to SST for data obtained by ICP-AES (gray circles and line) and LA-ICP-MS (black triangles and line).

6-month period (Fig. 3e). The extension rate from August to February is $10-12 \mathrm{~mm} / \mathrm{yr}$ which is significantly higher than 5-7 mm/yr from February to August. Compared to 1994-2009 and 1700-1711, the average $\mathrm{Sr} / \mathrm{Ca}$ ratio between $1671-1684$ is significantly higher, by $1.2 \%$, which corresponds to cooler conditions in particular during winter, as can be seen on the histograms (Fig. 3d). Although this piece of coral was not examined under the SEM, a nearby piece dated to the 1770 s as well as two other pieces around 1600 and 1620 were examined and show only pristine aragonite.

\section{Comparison between LA-ICP-MS and ICP-AES Sr/Ca ratio}

$\mathrm{Sr} / \mathrm{Ca}$ ratios measured by LA-ICP-MS and solution ICP-AES are compared in Fig. 4 and average values are reported in Table 1. There is an excellent agreement between the two methods for each time-window, including for the cooler period between 1671-1684. There are only few coral proxies covering that period (e.g., Hendy et al., 2002; Cobb et al., 2003). Similar variations of the temperature over a few decades during the LIA have been reported using compilations of other proxies from the Northern Hemisphere (Mann et al., 2009; Ljungqvist $e t$ al., 2012).

The consistency of the $\mathrm{Sr} / \mathrm{Ca}$ variations obtained by both methods excludes the possibility of a bias in the $\mathrm{Sr} /$ $\mathrm{Ca}$ ratios, and also implies that the $\mathrm{Sr} / \mathrm{Ca}$ compositions of two coral standard used here (JCp-1) and at ANU are accurate. The seasonal amplitude of the signal is slightly higher for $\mathrm{Sr} / \mathrm{Ca}$ measured by LA-ICP-MS, as expected from the smaller amount of powder analyzed. 
Sr/Ca-temperature calibration based on ICP-AES data and LA-ICP-MS data

We used the $\max / \mathrm{min}$ values of the $\mathrm{Sr} / \mathrm{Ca}$ record analyzed by ICP-AES to fit the data to the February/August SSTs (Fig. 5a). The corresponding least-square regression between $\mathrm{Sr} / \mathrm{Ca}$ and $\mathrm{SST}$ indicates a sensitivity of $-0.056 \mathrm{mmol} / \mathrm{mol} \mathrm{per}{ }^{\circ} \mathrm{C}$ (Fig. 6). This is within the range reported for tropical corals (Correge, 2006), most of these calibrations being obtained by similar solutionbased analysis of bulk coral powder. The calibration of $\mathrm{Sr} / \mathrm{Ca}$ to SST based on LA-ICP-MS was done using two different smoothed curves (Fig. 5b), as explained above. Both min/max $\mathrm{Sr} / \mathrm{Ca}$ values were obtained by binning a few data-points and in doing so, the winter proxy temperature may be slightly overestimated compared to monthly instrumental SST. Annual averages derived from these $\mathrm{min} / \mathrm{max} \mathrm{Sr} / \mathrm{Ca}$ values are consistent with annual mean SST for 1994-2008 within $1^{\circ} \mathrm{C}$ (Fig. 5c). It can be also noted that the anomalously warm summer of 1998 is well recorded by the coral (Figs. 5a and b). The calibration based on LA-ICP-MS gives a slightly stronger slope of $-0.068 \mathrm{mmol} / \mathrm{mol}$ per ${ }^{\circ} \mathrm{C}$, compared to that derived from ICP-AES data, the main difference being for the winter period (Fig. 6). This difference confirmed that the sampling resolution has a great effect on the slope of the SST calibration, as previously shown by Allison and Finch (2004). As a result, the annual mean proxy temperature derived from ICP-AES measurements is likely to be slightly overestimated (Fig. 5c). This highlights the advantage of the high spatial resolution laser ablation technique for temperate corals. It allows to capture more accurately the full annual range of temperature, in particular the winter signal. Another interesting outcome of this calibration is that there is no evidence that the $\mathrm{Sr} / \mathrm{Ca}$ record is affected by the change of extension rate from $\sim 5$ to $\sim 10 \mathrm{~mm} / \mathrm{yr}$ between winter and summer. This is in agreement with previous studies either in the field (e.g., Alibert and McCulloch, 1997; Hirabayashi et al., 2013) and using culture experiments (Hayashi et al., 2013).

\section{Conchusions}

We have shown that the LA-ICP-MS technique can provide high-precision $\mathrm{Sr} / \mathrm{Ca}$ records for multi-century temperate corals such as the Porites coral from Kikai Island. Careful analytical protocols are necessary, that include monitoring the presence of secondary aragonite and a strategy of replicates and overlaps between consecutive coral pieces. The long-term accuracy of the method was demonstrated by comparing LA-ICP-MS and ICPAES results for three time-windows, including a cooler period during the late 1600 s. As the LA-ICP-MS technique allows a rapid analysis of multiple elemental ratios, the consistency between separate temperature prox- ies provides another valuable quality control, and environmental parameters other than SST can also be monitored. The higher spatial resolution of the laser ablation technique is particularly well-adapted to temperate corals that produce very reduced skeletal growth during the winter months.

Acknowledgments-We thank T. Ijichi, K. Kubo and the government of Kikaicho when we collected samples in Kikai Islands. K. Abe, K. Minoshima, N. Hokanishi and Y. Yoshinaga provided laboratory assistance. Part of this research is supporeted from the grant by JSPS through the "Funding Program for Next Generation World-Leading Researchers (NEXT Program GR031)," initiated by the CSTP to Y.Y.

\section{REFERENCES}

Alibert, C. and Kinsley, L. (2008) A 170-year Sr/Ca and Ba/Ca coral record from the western Pacific warm pool: 1. What can we learn from an unusual coral record? J. Geophys. Res. 113, C04008, doi:10.1029/2006JC003979.

Alibert, C. and McCulloch, M. T. (1997) Strontium/calcium ratios in modern Porites corals from the Great Barrier Reef as a proxy for sea surface temperature: Calibration of the thermometer and monitoring of ENSO. Paleoceanography 12, 345-363.

Allison, N. and Finch, A. A. (2004) High-resolution Sr/Ca records in modern Porites lobata corals: Effects of skeletal extension rate and architecture. Geochem. Geophys. Geosyst. 5, Q05001, doi:10.1029/2004GC000696.

Beck, J. W., Edwards, R. L., Ito, E., Taylor, F. W., Recy, J., Rougerie, F., Joannot, P. and Henin, C. (1992) Sea-surface temperature from coral skeletal strontium/calcium ratios. Science 257(5070), 644-647.

Cobb, K. M., Charles, C. D., Cheng, H. and Edwards, R. L. (2003) El Niño-Southern Oscillation and tropical Pacific climate during the last millennium. Nature 424(6946), 271276.

Correge, T. (2006) Sea surface temperature and salinity reconstruction from coral geochemical tracers. Palaeogeogr. Palaeoclimatol. Palaeoecol. 232, 408-428.

DeLong, K. L., Quinn, T. M., Taylor, F. W., Lin, K. and Shen, C.-C. (2012) Sea surface temperature variability in the southwest tropical Pacific since AD 1649. Nature Climate Change 2, 799e804.

Fallon, S. J., McCulloch, M. T., van Woesik, R. and Sinclair, D. J. (1999) Corals at their latitudinal limits: laser ablation trace element systematics in Porites from Shirigai Bay, Japan. Earth Planet. Sci. Lett. 172, 221-238.

Fallon, S. J., McCulloch, M. T. and Alibert, C. (2003) Examining water temperature proxies in Porites corals from the Great Barrier Reef: a cross-shelf comparison. Coral Reefs 22, 389-404.

Felis, T., Suzuki, A., Kuhnert, H., Dima, M., Lohmann, G. and Kawahata, H. (2009) Subtropical coral reveals abrupt earlytwentieth-century freshening in the western North Pacific Ocean. Geology 37, 527-530, doi:10.1130/G25581A.1.

Gagan, M. K., Ayliffe, L. K., Hopley, D., Cali, J. A., Mortimer, 
G. E., Chappell, J., McCulloch, M. T. and Head, M. J. (1998) Temperature and surface-ocean water balance of the midHolocene tropical western Pacific. Science 279(5353), 1014-1018.

Hart, S. R. and Cohen, A. L. (1996) An ion probe study of annual cycles of $\mathrm{Sr} / \mathrm{Ca}$ and other trace elements in corals. Geochim. Cosmochim. Acta 60, 3075-3084.

Hayashi, E., Suzuki, A., Nakamura, T., Iwase, A., Ishimura, T., Iguchi, A., Sakai, K., Okai, T., Inoue, M., Araoka, D., Murayama, S. and Kawahata, H. (2013) Growth rate influences on coral climate proxies tested by a multiple colony culture experiment. Earth Planet. Sci. Lett. 362, 198-206.

Hendy, E. J., Gagan, M. K., Alibert, C. A., McCulloch, M. T., Lough, J. M. and Isdale, P. J. (2002) Abrupt decrease in tropical Pacific sea surface salinity at end of Little Ice Age. Science 295(5559), 1511-1514.

Hirabayashi, S., Yokoyama, Y., Suzuki, A., Kawakubo, Y., Miyairi, Y., Okai, T. and Nojima, S. (2013) Coral growthrate insensitive $\mathrm{Sr} / \mathrm{Ca}$ as a robust temperature recorder at the extreme latitudinal limits of Porites. Geochem. J. 47(3), e1-e5.

Jhun, J.-G. and Lee, E-.J. (2004) A new East Asian winter monsoon index and associated characteristics of the winter monsoon. J. Climate 17, 711-726.

Le Campion-Alsumard, T., Golubic, S. and Priess, K. (1995) Fungi in corals: symbiosis or disease? Interaction between polyps and fungi causes pearl-like skeleton biomineralization. Mar. Ecol. Prog. Ser. Oldendorf 117(1), 137-147.

Liu, Q., Xie, S.-P., Li, L. and Maximenko, N. A. (2005) Ocean thermal advective effect on the annual range of sea surface temperature. Geophys. Res. Lett. 32, L24604, doi:10.1029/ 2005 GL024493.

Ljungqvist, F., Krusic, P., Brattström, G. A. and Sundqvist, H. (2012) Northern Hemisphere temperature patterns in the last 12 centuries. Climate of the Past 8, 227-249.

Mann, M. E., Zhang, Z., Rutherford, S., Bradley, R. S., Hughes, M. K., Shindell, D., Ammann, C., Faluvegi, G. and Ni, F. (2009) Global signatures and dynamical origins of the Little Ice Age and Medieval climate anomaly. Science 326(5957), 1256-1260.

Mantua, N. J., Hare, S. R., Zhang, Y., Wallace, J. M. and Francis, R. C. (1997) A Pacific interdecadal climate oscillation with impacts on salmon production. Bull. Am. Meteorol. Soc. 78, 1069-1079.

Meibom, A., Cuif, J.-P., Houlbreque, F., Mostefaoui, S., Dauphin, Y., Meibom, K. L. and Dunbar, R. (2008)
Compositional variations at ultra-structure length scales in coral skeleton. Geochim. Cosmochim. Acta 72, 1555-1569, doi:10.1016/j.gca.2008.01.009.

Nurhati, I. S., Cobb, K. M. and Di Lorenzo, E. (2011) Decadalscale SST and salinity variations in the central tropical $\mathrm{Pa}-$ cific: Signatures of natural and anthropogenic climate change. J. Climate 24, 3294-3308.

Okai, T., Suzuki, A., Kawahata, H., Terashima, S. and Imai, N. (2002) Preparation of a new geological survey of Japan geochemical reference material: Coral JCp-1. Geostand. Newsl. 26, 95-99.

Qiu, B. (2000) Interannual variability of the Kuroshio Extension system and its impact on the sintertime SST field. $J$. Phys. Oceanogr. 30, 1486-1502.

Qiu, B. (2003) Kuroshio Extension variability and forcing of the Pacific Decadal Oscillations: Responses and potential feedback. J. Phys. Oceanogr. 33, 2465-2482.

Reynolds, R. W., Rayner, N. A., Smith, T. M., Stokes, D. C. and Wang, W. (2002) An improved in situ and satellite SST analysis for climate. J. Climate 15, 1609-1625.

Schrag, D. P. (1999) Rapid analysis of high-precision Sr/Ca ratios in corals and other marine carbonates. Paleoceanography 14, 97-102.

Seki, A., Yokoyama, Y., Suzuki, A., Kawakubo, Y., Okai, T., Miyairi, Y., Matsuzaki, H., Namizaki, N. and Kan, H. (2012) Mid-Holocene sea-surface temperature reconstruction using fossil corals from Kume Island, Ryukyu, Japan. Geochem. J. 46(3), e27-e32.

Sinclair, D. J. (2005) Correlated trace element "vital effect" in tropical corals: A new geochemical tool for probing biomineralization. Geochim. Cosmochim. Acta 69, 32653284.

Sinclair, D. J., Kinsley, L. P. J. and McCulloch, M. T. (1998) High resolution analysis of trace elements in corals by laser ablation ICP-MS. Geochim. Cosmochim. Acta 62, 18891901.

Wall, M. and Nehrke, G. (2012) Reconstructing skeletal fiber arrangement and growth mode in the coral Porites lutea (Cnidaria, Scleractinia): a confocal Raman microscopy study. Biogeosciences 9, 4885-4895.

Yokoyama, Y., Suzuki, A., Siringan, F., Maeda, Y., Abe-Ouchi, A., Ohgaito, R., Kawahata, H. and Matsuzaki, H. (2011) Mid-Holocene palaeoceanography of the northern South China Sea using coupled fossil-modern coral and Atmosphere-Ocean GCM model. Geophys. Res. Lett. 38, L00F03, doi:10.1029/2010GL044231. 